\title{
MIDAS
}

Museus e estudos interdisciplinares

$7 \mid 2016$

Varia

\section{O que quer que se diga sobre Rui Mário Gonçalves não é tudo...}

Everything we can say about Rui Mário Gonçalves is not enough...

\section{Filipa Coimbra e Joana Baião}

\section{(2) OpenEdition}

\section{Journals}

\section{Edição electrónica}

URL: http://journals.openedition.org/midas/1123

DOI: 10.4000/midas. 1123

ISSN: 2182-9543

\section{Editora:}

Alice Semedo, Paulo Simões Rodrigues, Pedro Casaleiro, Raquel Henriques da Silva, Ana Carvalho

\section{Refêrencia eletrónica}

Filipa Coimbra e Joana Baião, «O que quer que se diga sobre Rui Mário Gonçalves não é tudo... », MIDAS [Online], 7 | 2016, posto online no dia 29 novembro 2016, consultado no dia 01 maio 2019 URL : http://journals.openedition.org/midas/1123; DOI : 10.4000/midas.1123

Este documento foi criado de forma automática no dia 1 Maio 2019

\section{(c) (i) (2)(2)}

Midas is licensed under a Creative Commons Attribution-NonCommercial-ShareAlike 3.0 International License 


\section{O que quer que se diga sobre Rui Mário Gonçalves não é tudo...}

Everything we can say about Rui Mário Gonçalves is not enough...

Filipa Coimbra e Joana Baião

NOTA DO EDITOR

Artigo recebido a 31.03.2015

Aprovado para publicação a 01.02.2016
TODAS AS POSSÍVEIS POSSIBILIDADES

Ao Rui Mário Gonçalves

Todas as possíveis possibilidades de ver

Claras e sóbrias

Se unem e resultam

Determinadas, como uma árvore

Sem folhas:

Porque tendem todas para os dedos do espaço, Porque atingiram o ser do nervo,

A textura única.

Facilidade pura.

Olhá-las é um ato

De nervos límpidos:

Estaladas,

Cantam.

Chegaram a si mesmas,

Hastes e panos,

Uma vela

De veias

Retilínea. 
1 Há nomes incontornáveis, que ora aparecem «Encadernados», sublinhados ou apenas subentendidos, com os quais nos deparamos recorrentemente quando temos como objeto de estudo as exposições promovidas pela Fundação Calouste Gulbenkian (FCG), nestes 59 anos de laboriosa atividade (1956-2015). Um desses nomes é, sem hesitações, o do crítico e historiador Rui Mário Gonçalves (1934-2014) que, inesperadamente, nos deixou em 2014. Foi este crítico atento quem, no prefácio do catálogo da exposição Seis Pintores Portugueses de Paris, concluiu de forma inequívoca: «O que quer que se diga sobre as obras, não é tudo...» (Gonçalves 1966b, s/p).

Ora, o mesmo raciocínio lhe é devido, agora, quando a nossa atenção recai na sua ativa e multifacetada relação com a FCG. Mais do que a justa homenagem que merece, cabe-nos, num projeto de investigação e inventariação com a dimensão do projeto "RaisExpo Catálogo Raisonné Online das Exposições de Arte da Fundação Calouste Gulbenkian" ${ }^{\text {, }}$ tornar público o seu legado, as suas contribuiç̃oes e parcerias estabelecidas com esta instituição durante vários anos.

3 Este artigo é fruto de uma primeira abordagem a uma parte do rico acervo documental existente na FCG, nomeadamente ao nível das exposições e o processo de Rui Mário Gonçalves enquanto bolseiro desta instituição. Esta abordagem foi complementada com o levantamento sistemático da fortuna crítica produzida por esta personalidade no âmbito das exposições promovidas pela Fundação. Os dados e as ideias que serão apresentados refletem a natureza inconstante da documentação consultada: os processos variam em complexidade e em extensão, não refletindo necessariamente a importância de cada evento registado. Esta opção metodológica reflete-se no enfoque e grau de aprofundamento dos temas enunciados.

4 Licenciado em Ciências Físico-Químicas pela Universidade de Lisboa, desde cedo que Rui Mário Gonçalves revelou particular interesse pela área das artes plásticas. Ainda estudante, na década de 1950, foi responsável pela secção cultural da Associação de Estudantes da Faculdade de Ciências de Lisboa. Começou então a organizar exposições coletivas de artistas portugueses, das quais se destacou a Primeira Retrospetiva de Pintura Não-Figurativa Portuguesa (1958).

5 Mais tarde, em 1961, começou a intervir como crítico de arte, vindo a colaborar com mais ou menos regularidade em diversos periódicos nacionais, entre os quais: Jornal de Letras e Artes, A Capital, Diário de Notícias, Colóquio/Artes, Arquitetura: Revista de arte e construção, JL, Artes e Ideias e Expresso. Para além disso, foi curador de inúmeras exposições, elaborou catálogos e monografias, redigiu textos e ensaios e foi responsável pelo impulso da carreira de vários artistas. Entre os importantes contributos que trouxe para a crítica e para a historiografia da arte portuguesa, refira-se a «atenção que teve para com a arte abstrata (geométrica e não-geométrica) contrariando a dominante (neo)realista da cultura portuguesa» e o destaque que deu «ao vasto leque de sensibilidades derivadas do surrealismo português, a partir desses mesmos anos 1950 e que, nas duas décadas seguintes, marcadas por outras correntes internacionais, se revelaram em toda a sua vitalidade» (Pinharanda 2014, s/p).

6 A par destas ações, Rui Mário Gonçalves colaborou com diversas instituições artísticas nacionais como, por exemplo, a Gravura - Sociedade Cooperativa de Gravadores Portugueses, de que foi membro do Conselho Técnico, e desenvolveu uma intensa atividade de docência. Lecionou no Curso de Formação Artística da Sociedade Nacional de 
Belas-Artes (1967-1986), foi professor nas Escolas de Teatro e Cinema do Conservatório Nacional (1972-1977) e no departamento de Literaturas Românicas da Faculdade de Letras Universidade de Lisboa (a partir de 1974).

7 Focando a ação de Rui Mário Gonçalves em torno da FCG, verificamos que são ténues as linhas que a separam do panorama mais lato da cultura artística nacional, ou seja, das responsabilidades partilhadas com outros organismos culturais, públicos e privados. Não esqueçamos, pois, para além das atividades acima mencionadas, o seu envolvimento com o «experimentalismo galerístico» (Pena 1994, s/p), designadamente durante o período em que foi diretor artístico da Galeria Buchholz (1966-1975) ${ }^{2}$, a sua atividade na Secção Portuguesa da Associação Internacional de Críticos de Arte (AICA) - da qual foi, inclusivamente, por duas vezes, presidente (1971-1973; 1998-2001) - e, em tantos outros domínios institucionais, ou despretenciosamente conviviais da vida artística nacional, nos quais tão gentil e ativamente se movia.

\section{Prémio Calouste Gulbenkian de Crítica de Arte (1963) e as «Artes Plásticas» do Jornal de Letras e Artes}

Foi em 1963 que se deu a primeira aproximação de Rui Mário Gonçalves à FCG no âmbito da segunda edição do concurso Prémio Calouste Gulbenkian de Crítica de Arte ${ }^{3}$.

A criação de um Prémio com o nome do fundador que distinguisse a produção crítica na imprensa escrita, para além de inovador foi de extrema importância para os esforços de reconhecimento e profissionalização da atividade da crítica da arte - à época, tantas vezes confundida com o amadorismo erudito e causticada pelo academismo reinante ${ }^{4}$.

Rui Mário Gonçalves submeteu à FCG, a fim de serem avaliados pelo júri do Prémio, dez artigos que publicara na secção de «Artes Plásticas» do Jornal de Letras e Artes, com o qual vinha colaborando desde o primeiro número (outubro de 1961). Três dos artigos enviados resultavam da sua reflexão crítica acerca de duas das mais significativas exposições promovidas pela FCG nos seus primeiros anos de existência: a II Exposição de Artes Plásticas da FCG $(1961)^{5}$ e a exposição Arte Britânica do Século XX (1962)6 ${ }^{6}$ O Prémio acabou por lhe ser atribuído pelo exigente painel de jurados - composto por Delfim Santos, Frederico George, Armando Vieira Santos, Adriano de Gusmão e Mário Dionísio - e constituiu um marco na sua carreira, uma vez que, para além de validar publicamente o reconhecimento dos seus méritos enquanto crítico, com o "selo" prestigiante da Fundação, acabaria por estreitar as relações entre ambos. Este foi o primeiro grande impulso da sua carreira, fixando-se como o evento que o afastou de um certo isolamento que sentia na sua atividade:

Fiquei satisfeito ao ver quebrada a minha solidão de crítico. [...] a solidão do crítico é algo de que nem sempre se fala. É importante sabermos que o que escrevemos é considerado pertinente pelos outros. ("Entrevista com Rui Mário Gonçalves" 1963, 1)

11 A própria redação do Jornal de Letras e Artes viria a regozijar-se pelo Prémio atribuído ao seu jovem colaborador:

Entre os diversos trabalhos concorrentes, o júri, [...] escolheu um trabalho publicado pelo nosso crítico Rui Mário Gonçalves [...]. O «Jornal de Letras e Artes» congratula-se especialmente por esta decisão do júri, por se tratar de um colaborador assíduo e por ver confirmada publicamente a confiança que depositou 
em Rui Mário Gonçalves ao confiar-lhe, apesar da sua juventude, uma tribuna de

crítica. ("Prémio de Crítica de Arte Rui Mário Gonçalves" 1963, 5) par de Arquitetura: Revista de Arte e Construção, de Colóquio. Revista de Artes e Letras (editada pela F(G), e de um ou outro "oásis" de residual tiragem na imprensa escrita nacional, como ferramenta essencial para iniciação de públicos e para a renovação do pensamento artístico e crítico da época.

13 Simultaneamente às responsabilidades exercidas na «Secção de Artes Plásticas» do Jornal de Letras e Artes ${ }^{7}$, Rui Mário Gonçalves começou a colaborar ocasionalmente com a revista Colóquio. Revista de Artes e Letras. O crítico publicou vários artigos nesta publicação no início da década de 1960, mais assiduamente no ano de 1963. Contudo, a sua colaboração nesta revista só viria a tornar-se mais constante na década de 1970, principalmente a partir de 1977, ano em que substituiu Fernando Pernes na rubrica «Cartas de Lisboa» (Alves 2007, 59). Em 2006, num balanço sobre os 50 anos da atividade da FCG, Rui Mário Gonçalves destacaria a importância desta publicação que, nas suas palavras «estava em condições de se tornar uma das melhores revistas do mundo, senão a melhor [...]» (Gonçalves 2006, 21).

14

O nome de Rui Mário Gonçalves esteve ligado, ora como colaborador permanente, ora em colaborações ocasionais, a este universo editorial de referência da cultura artística nacional. E, com ele, outros nomes surgiram e afirmaram-se neste período, sendo de assinalar a correlação entre o desenvolvimento da crítica da arte, por via destas publicações, e a atribuição dos Prémios Calouste Gulbenkian de Crítica de Arte (Rodrigues 1994; Rosendo 2012) ${ }^{8}$.

15 Estas articulações entre os jovens críticos e a FCG seriam também estreitadas com o incremento da política de atribuição de bolsas de estudo e de especialização concedidas pela FCG, de que Rui Mário Gonçalves viria a beneficiar.

\section{A bolsa de especialização em Paris: 1963-1966}

16 Mediante carta manuscrita, datada de 11 de abril de 1963, Rui Mário Gonçalves remeteu ao Serviço de Belas Artes da FCG o seu programa de candidatura a uma bolsa de especialização em Paris, a que anexou as recomendações de Fernando Pernes e de JoséAugusto França, próximos do seu círculo profissional e social, membros de uma renovada geração de críticos e conhecedores das correntes do pensamento crítico parisiense?.

O seu programa de estudos incidia essencialmente na frequência do curso de Sociologia da Arte da École Pratique des Hautes Études, tutelada pelo crítico Pierre Francastel. Em complementaridade, Gonçalves comprometia-se ainda a frequentar outros cursos, em instituições como a École du Louvre, o Collège de France e o Institut d'Art et d'Archéologie. A Comissão Consultiva da FCG aprovou a sua proposta em setembro $1963^{10}$.

18 A concessão desta bolsa viria a ter importantes ecos no percurso formativo de Rui Mário Gonçalves. No campo da aquisição de competências, interessa salientar, por um lado, o seu exemplar percurso académico, marcado pela frequência regular das aulas e das conferências proferidas por Pierre Francastel, Roland Barthes, Jean Cassou, René Huyghe, Maurice Sérullaz, Bernard Dorival, Roseline Bacou, Suzanne Bachelard e Henri GalyCarles, tal como testemunham os relatórios que enviava regularmente à FCG.

MIDAS, 7 | 2016 
19 Por outro lado, destaque-se a sua integração no ambiente de dinâmico convívio artístico parisiense, sobretudo com os jovens artistas portugueses. Este ambiente foi largamente potenciado pelo incremento da política de atribuição de bolsas a artistas e críticos assumido pela FCG, e cuja primeira grande vaga se dirigiu, maioritariamente, para a capital francesa. Em Paris, durante o período em que foi bolseiro FCG, Rui Mário Gonçalves frequentou assiduamente os ateliês de vários artistas portugueses, não só os dos bolseiros, ou ex-bolseiros da Fundação - entre os quais René Bértholo, Gonçalo Duarte (mais tarde), Lourdes Castro, José Escada, João Vieira, Manuel Batista, Manuel Cargaleiro, Eduardo Luiz - mas também os de Sérgio Camargo, de Martha Telles ou de Jorge Martins. E visitou também ateliês de artistas de outras nacionalidades, como Jan Voss (elemento dos KWY), Jean Degottex, Jean Dupuy, Marcelle Cahn ou René Duvillier. Tudo isto acabaria por ter implicações na evolução da sua atividade enquanto crítico e no modo determinante como acabou por contribuir para inscrever alguns destes jovens artistas na história da arte portuguesa do pós-guerra.

20 Foi na sequência destas visitas regulares a ateliês que Rui Mário Gonçalves iniciou a publicação no Jornal de Letras e Artes de entrevistas a artistas, marcadas pelo tom informal e pelo destaque dado à evolução individual dos percursos artísticos, os diferentes processos criativos e as problemáticas e influências de artistas diversos ${ }^{11}$. Esta série de entrevistas, iniciada no ano de 1964, coincidiu com um período quente da crítica internacional: a querela dos centros artísticos - Paris versus Nova Iorque - para a qual a exposição Painting and Sculpture of a Decade: 1954-64, organizada pela FCG na Tate Gallery (1964) contribuiu, ao inflamar as críticas na imprensa nacional e internacional ${ }^{12}$.

21 Refira-se que, subsidiado pela FCG para se deslocar a Londres, Rui Mário Gonçalves viria a assumir o seu posicionamento neste debate na crítica que publicou em Arquitetura: Revista de Arte e Construção, em novembro de 1964. Mais moderado do que José-Augusto França ${ }^{13}$, o jovem crítico demarcou-se da ferocidade dos comentários vindos de Paris (ainda que fizesse «alguns reparos» relativamente à excessiva representatividade de artistas ingleses e americanos no certame), revelando-se até interessado pela renovação artística norteamericana ("Rui Mário Gonçalves" 1964, 12 e 16). Assim, reconhecia a vitalidade e dinamismo do ambiente artístico parisiense durante a década a que reportava a exposição, ressalvando contudo, que essa proeminência seria herança de acontecimentos geo-políticos específicos, que deram enquadramento a uma hegemonia cultural francesa no século XIX e na primeira metade do século $\mathrm{XX}^{14}$. Ainda que neste contexto Rui Mário Gonçalves simultaneamente constatasse a efetiva e, até, "vantajosa» descentralização artística que se vinha verificando na última década, referindo a «notoriedade legítima adquirida pela pintura americana» e chamando mesmo a atenção para a «pop-art abstrata» e para o vanguardismo das propostas neo-dádá de Rauschenberg e de Jasper Johns ("Prémio Gulbenkian Crítica de Arte" 1964, 16).

O destaque dado, através da sua atividade periodística, a toda a efervescência artística internacional, aos jovens artistas, à evolução das suas práticas e as indicações sobre o seu universo de referências, contribuiu largamente para o arejamento e renovação que se fizeram sentir na cultura artística nacional em meados da década de 1960. E essa atividade seria intensificada após o fim da bolsa e do seu regresso a Portugal, com a organização de exposições. Destas, destaca-se a exposição Seis Pintores Portugueses de Paris, que comissariou em setembro de 1966 na Galeria Buchholz. Composta por obras de René Bértholo, Manuel Cargaleiro, Lourdes Castro, Eduardo Luís, José Escada e Jorge Martins, esta mostra salientava a produção dos «jovens pintores que estão agora em Paris, com os 
olhos abertos, rasgados para o futuro» (Gonçalves 1966b, s/p) e tinha um objetivo bem claro: revelar a "autenticidade» destes artistas, a atualidade dos seus trabalhos e afirmar de forma decisiva a importância das influências apreendidas no estrangeiro, ressaltando que o «abandono nunca é total e, se a sua presença entre nós se torna mais rara, tem melhor qualidade» ("Rui Mário Gonçalves" 1964, 16).

Como António Rodrigues destacou no texto de catálogo da exposição Anos 60. Anos de Ruptura: «Rui Mário Gonçalves foi sem dúvida o crítico da década» (Rodrigues 1994, s/p). Sem hesitações: foi-o pela sua capacidade de refletir sobre as gerações de artistas modernos já confirmadas; pela atenção às práticas de aproximação entre a figuração e abstração; e pelo seu espírito curioso e analítico, centrado nas novas problemáticas plásticas e conceptuais sobre as quais os jovens artistas se detinham. Nas suas próprias palavras: «o artista e o crítico estão muito atentos ao fazer e o fazer que envolve as capacidades todas do artista, que nem sempre sabe a quê que obedece» (Gonçalves 2014, $\mathrm{s} / \mathrm{p})$.

\section{Finais da década de 1960 e os anos 1970}

24 Já a avançar para o final da década de 1960, assinalamos um acontecimento que é impossível de desligar da atividade de Rui Mário Gonçalves e do incremento dado à afirmação da crítica de arte em Portugal: o I Encontro de Críticos de Arte Portugueses ${ }^{15}$. Deste Encontro saíram disposições e moções que foram entregues à $\mathrm{FCG}^{16}$ - que nunca viria a implementá-las de forma programática -, reveladoras do dinamismo e da formação destes novos agentes da crítica, motivados em participar ativamente em todos os domínios da vida artística nacional, afirmando, por essa via, a sua profissionalização ${ }^{17}$. Nesse sentido, a articulação com a Fundação seria indiscutivelmente necessária, quando não essencial, uma vez que o desnorte governamental destacava sobejamente a Gulbenkian como «via para-oficial» (Pernes s/d, 35) da iniciativa e divulgação artística nacionais.

Muito haveria a dizer sobre este Encontro de 1967, até porque inaugurou uma nova fase da crítica da arte em Portugal que se prolongou por toda a década seguinte. Esta atitude voluntarista de recentramento crítico conduziria, posteriormente, à reestruturação da Secção Portuguesa da $\mathrm{AICA}^{18}$, que se posicionaria ativamente na imprensa escrita através do suplemento «Pintura \& Não» da revista Arquitetura -, assim como noutros domínios (v. Macedo 2009, 19-20). Acompanhando este momento de viragem, Rui Mário Gonçalves assumiria, em 1971, a presidência da AICA, sucedendo a José-Augusto França (v. Rosendo 2012).

Todos estes temas terão, invariavelmente, interligação com a atividade da FCG, atendendo à amplitude do seu raio de ação e à proximidade entre os quadros dos dois organismos. Desta interação entre a AICA e a FCG resultariam algumas realizações relevantes, como a promoção do Congresso Internacional da AICA, em 1976, e várias outras parcerias, a subsidiação de projetos e exposições.

Estas movimentações no sentido de profissionalizar a crítica de arte, dotando-a de instrumentos institucionais capazes de lhe conferir uma certa autonomia, foram também impulsionadas pelo novo período de atividade expositiva da FCG após a inauguração das suas novas instalações, em 1969. O evento fundador foi uma exposição há muito aguardada no meio artístico nacional: a primeira retrospetiva, em Portugal, da obra de Maria Helena Vieira da Silva. 
No âmbito desta excecionalmente bem-sucedida exposição ${ }^{19}$, a "nova crítica" foi chamada a participar numa mesa-redonda sobre a obra da pintora, concebida «como um marco importante na história das relações da arte moderna com o público português» (Gonçalves 1970, 1). Integrando o debate, em que também participaram José-Augusto França, Adriano de Gusmão, Fernando Pernes, Fernando de Azevedo, Rocha de Sousa e Pedro Vieira de Almeida, Rui Mário Gonçalves procurou salientar a necessidade de naquele momento e naquele ambiente especializado se «recolocar o problema da função e validade da arte», e de se questionar o papel da crítica em «fazer o público» (idem). Era, pois, bastante claro o modo como Gonçalves encarava o seu papel de crítico: a crítica só faria sentido se se destinasse ao público - a um público que compreendesse, interpretasse ou que refutasse o que lhe era comunicado. Os esforços dos críticos deveriam, então, ser concentrados na formação e na auscultação do público.

Os vários dados que temos vindo a referir dão-nos uma ideia das articulações entre os grandes promotores de eventos artísticos nacionais, entre os quais a FCG, e o processo de institucionalização da crítica de arte e de exposições. Assim, se é verdade que a crítica, na sua versão profissionalizada e com um papel ativo na sociedade, se desenvolveu com a FCG e precisava desta para se "fazer ouvir", é igualmente acertado considerar que a FCG também beneficiava dos esforços desta "nova crítica" na validação da sua atividade no panorama artístico nacional. Este entendimento era claro para todos, o que permitia à AICA a "ousadia" de questionar algumas metodologias e de apresentar propostas e moções à FCG que, por sua vez, tinha sempre a última palavra, sem admitir ingerências internas à sua administração, ou ao seu programa.

Por fim, saliente-se ainda neste ponto o papel ativo e polivalente de Rui Mário Gonçalves nas atividades da FCG no início da década de 1970. Num contacto mais direto com o público, ou em manifestações a ele destinadas, participou como crítico destacado em inúmeras visitas guiadas, entre as quais às exposições: Vieira da Silva (1970); 100 Obras de Arte Britânica Contemporânea da Fundação Calouste Gulbenkian (1971) (fig. 1); Arte Francesa Depois de 1950 (1971); Naum Gabo (1972); Sonia e Robert Delaunay em Portugal e os seus Amigos: Eduardo Vianna, Amadeo de Souza-Cardoso, José Pacheco e Almada Negreiros (1972); Dada.1916-1966 (1972); e Paul Klee 1879-1940 (1972) ${ }^{20}$ (fig. 2). 


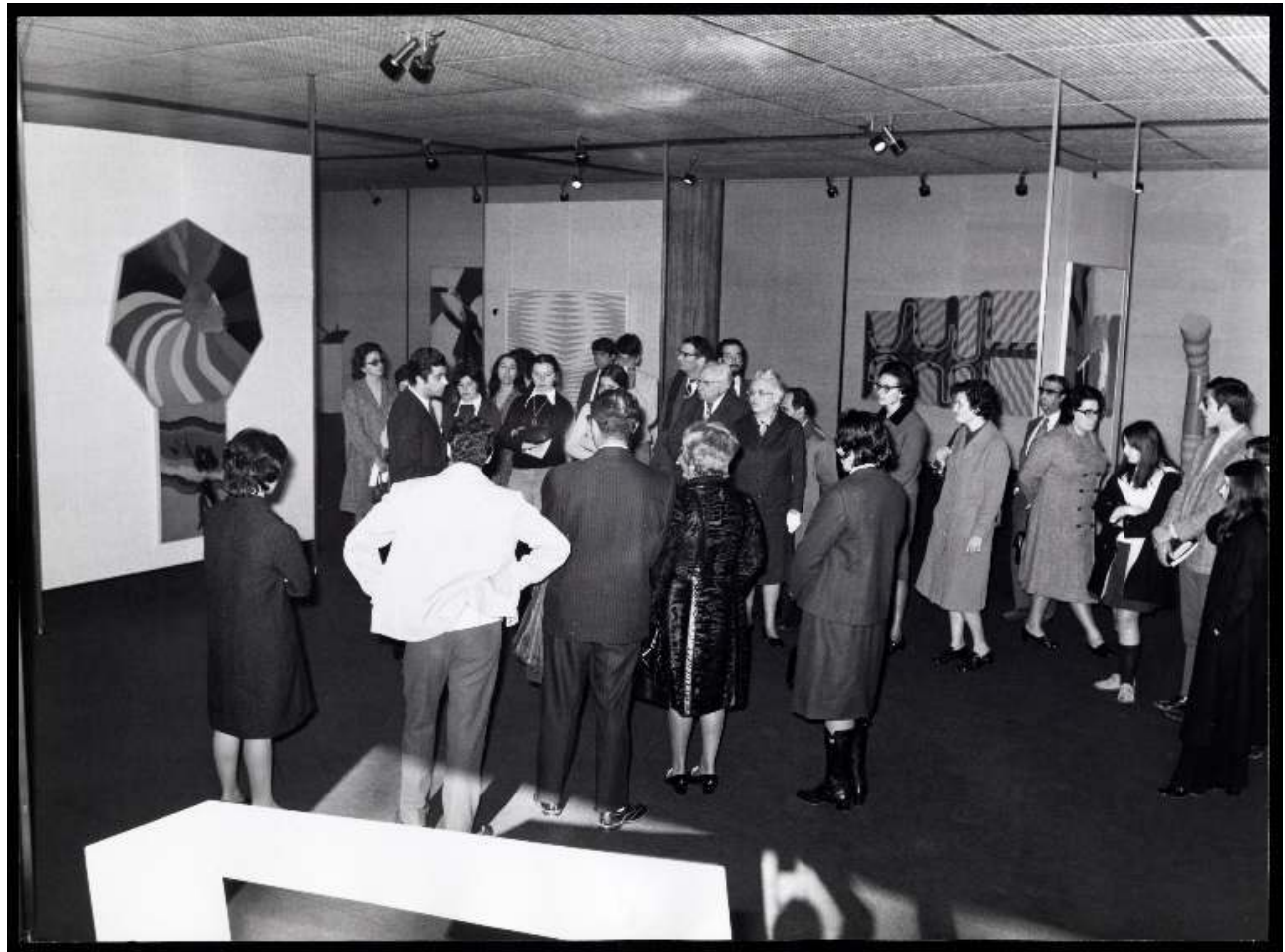

Fig. 1 - Rui Mário Gonçalves a orientar uma visita guiada à exposição 100 Obras de Arte Britânica Contemporânea. FCG, 1971

(c) Fotografia de Carlos Coelho da Silva, Arquivo da FCG

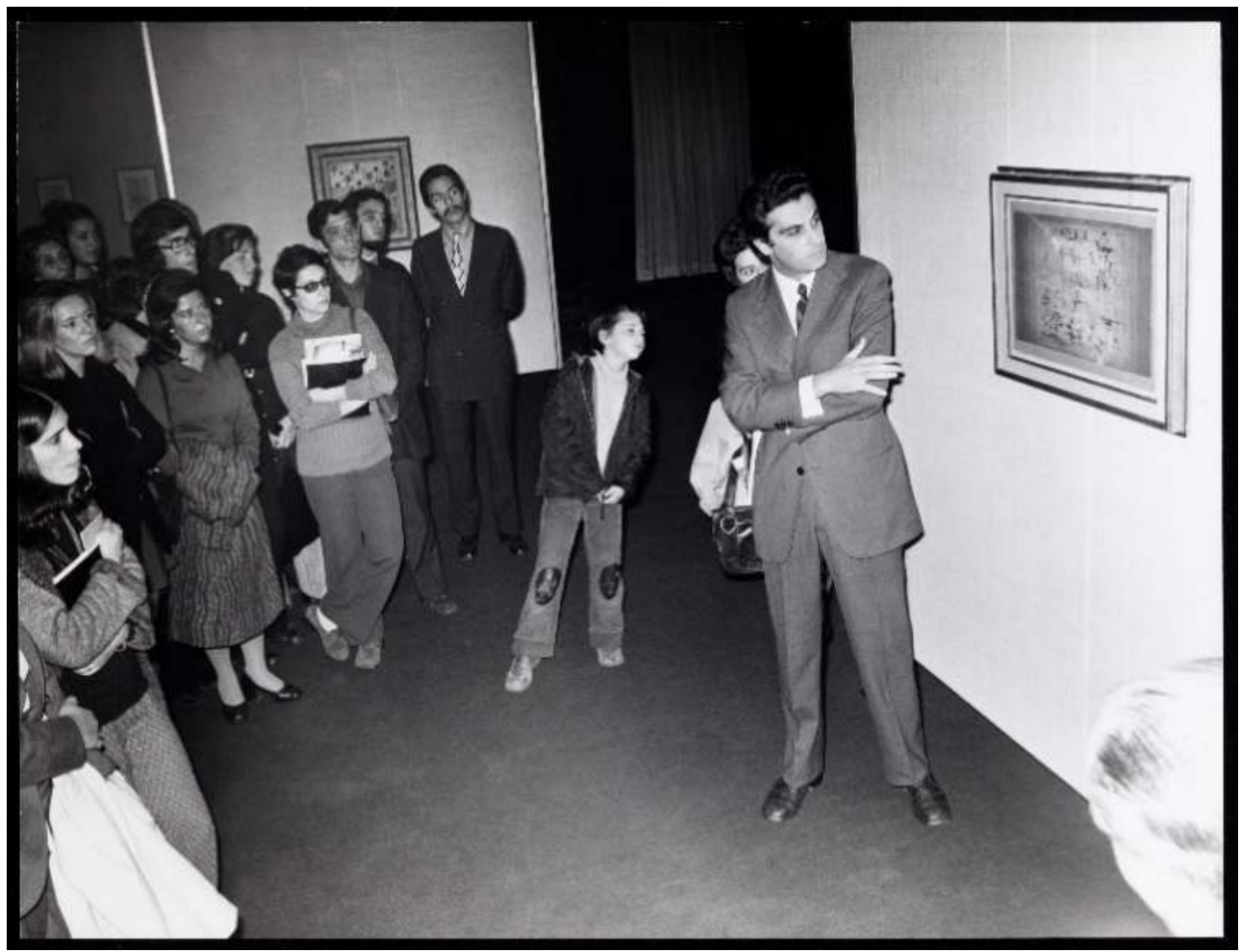

Fig. 2 - Rui Mário Gonçalves a orientar uma visita guiada à exposição Paul Klee. FCG, 1972 (c) Fotografia de Carlos Coelho da Silva, Arquivo da FCG

31 Rui Mário Gonçalves participou também como orador em conferências, tais como: Mecanismos da Criação Artística, realizada em 1971 enquanto atividade complementar à 
exposição Nadir Afonso, ou na Mesa-redonda sobre a Obra de Joan Miró, integrada nas atividades complementares à exposição A Obra Gráfica de Miró (1974). E produziu numerosos textos para catálogos de exposições, entre os quais: Pintura Portuguesa de Hoje. Abstratos e Neofigurativos (1973); Gravure Portugaise Contemporaine 1970-1975 (Paris, 1975); e Arte Moderna Portuguesa - Obras Pertencentes às Coleções da Secretaria de Estado da Cultura e da Fundação Calouste Gulbenkian (Sociedade Nacional de Belas Artes, 1979). Destaque-se ainda a participação regular de Gonçalves na revista Colóquio, desde o n.․ 21 (dezembro de 1962), com críticas de arte, e textos sobre exposições e ensaios.

Esta breve cronologia sintetiza bem a sua extensa e diversificada atividade junto da FCG neste período, anterior à criação do Centro de Arte Moderna, que tanto desejou e congratulou. Esta intensa ação foi acompanhada por outras atividades independentes na Sociedade Nacional de Belas-Artes, na direção artística da galeria Buchholz (até 1975), e no jornal A Capital, onde escreveu com regularidade textos críticos no suplemento «Literatura \& Arte». Foi também durante estes anos (1979-1980) que colaborou com a Galeria Quadrum, de Dulce D'Agro, orientando um curso semestral subsidiado pela FCG, subordinado ao tema "Aspetos e Problemas da Arte Moderna".

\section{Centro de Arte Moderna José de Azeredo Perdigão (1983) e o ACARTE - Serviço de Animação, Criação Artística e Educação pela Arte (1984)}

O Centro de Arte Moderna José de Azeredo Perdigão (CAMJAP) foi inaugurado em 1983, respondendo ao atraso estrutural de que padecia a cultura artística nacional. Cumpria-se, assim, um dos grandes desígnios da FCG - dotar o país de um espaço expositivo verdadeiramente consagrado à arte moderna e às manifestações da contemporaneidade. José Sommer Ribeiro assumiu a direção do novo centro, contando com a colaboração de uma nova geração de historiadores e críticos de arte (como João Pinharanda, António Cerveira Pinto ou Alexandre Melo), que seria fundamental para definir uma programação empenhada em cruzamentos e diálogos multidisciplinares, tão ausentes e tão necessários ao desenvolvimento da cultura artística nacional. No ano seguinte, e para melhor fazer jus a esta missão, foi criado internamente o Serviço de Animação, Criação Artística e Educação pela Arte (ACARTE), proposta há muito defendida por Madalena Perdigão, que se encarregou da sua orientação.

Rui Mário Gonçalves colaborou com este «lugar aberto ao experimentalismo», como o próprio referiu (Gonçalves 2006, 20), comissariando algumas exposições em complementaridade com uma programação mais lata e transdisciplinar. São disso exemplo as exposições O Imaginário da Cidade de Lisboa (1985) e O Fantástico na Arte Contemporânea Portuguesa (1986). Para além disso, escreveu textos para algumas exposições antológicas que tiveram lugar na FCG, tais como: Helena Almeida (1983), António Dacosta (1988); e Álvaro Lapa: Obras Sobre Papel (1989) -, participou em mesas-redondas e colóquios, e integrou o júri de seleção de obras da terceira e última Exposição de Artes Plásticas $^{21}$. O seu último papel de relevo na FCG foi a organização da exposição Arte Portuguesa nos Anos 50 (Biblioteca Municipal de Beja, 1992; Sociedade Nacional de Belas Artes, 1993), organizada em parceria com a Câmara Municipal de Beja, que permitiu que a «década do silêncio» saísse do obscurantismo em que estava envolta, suscitando o interesse da crítica especializada. 
nvite para comissariar esta exposição constituiu uma exceção na relação entre a FCG e Rui Mário Gonçalves - tal como seria excecional a sua integração na comissão científica do ambicioso projeto "Catalogue Raisonné de Amadeo de Souza-Cardoso" (Freitas e Molder 2007; Freitas e Molder 2008). O abrandamento na interação do crítico com a Fundação é atestado pela diminuição de registos no acervo da própria instituição, a partir dos finais da década de 1970. Este gradual afastamento das atividades da FCG pode ser relacionado com um fenómeno de substituição geracional na crítica da arte portuguesa, já enunciado por Raquel Henriques da Silva, que considera que, na consequência da exposição Alternativa Zero e da nova abordagem crítica de Ernesto de Sousa, simbolicamente se «encerrava o poderoso consulado de José-Augusto França e dos seus discípulos mais diretos que a dominaram desde finais dos anos 50» (Silva 2009, 30).

\section{Considerações finais}

No contexto das celebrações do 50. aniversário da FCG, Rui Mário Gonçalves exprimiu algumas considerações relativamente ao papel desta instituição no panorama artístico nacional com a lucidez que lhe era característica (Gonçalves 2006, 20-21). Nessa análise retrospetiva, evidenciou alguns dos momentos partilhados, destacando, desde logo: as grandes exposições - como, por exemplo, o «inquérito à situação das artes» que foi a Primeira Exposição de Artes Plásticas ${ }^{22}$; a abertura à (ou a tentativa de) internacionalização da arte portuguesa, através da política de concessão de bolsas de estudo a artistas e críticos; os subsídios orientados a outras instituições artísticas (tais como a Gravura Sociedade Cooperativa de Gravadores Portugueses ou a SNBA); a publicação da revista Colóquio/Artes; e, por fim, a criação do CAM, esse «marco na história da arte moderna portuguesa»e «lugar aberto ao experimentalismo» (Gonçalves 2006, 21).

Em certa medida, pode-se afirmar que houve uma simultaneidade entre a definição do papel artístico da recém-criada FCG (1956) e a afirmação de Rui Mário Gonçalves enquanto jovem crítico. Esta simbiose terá sido bastante proveitosa para ambos e, acima de tudo, para o público que beneficiou largamente destes ensejos.

Rui Mário Gonçalves consagrou a sua atividade à afirmação da crítica da arte portuguesa, revelando pleno conhecimento da arte moderna em Portugal e do seu diálogo com a cena internacional. E mais do que isso, apostou numa inédita vertente formativa, defendendo uma maior proximidade dos públicos. Em vários momentos, a sua missão pessoal encontrou na FCG o lugar ideal para se desenvolver.

Fica muito por analisar e outro tanto por refletir neste texto em que procurámos sintetizar a intervenção daquele que foi um dos críticos de arte de referência portugueses. Devem ser enunciadas linhas de pesquisa para futuras investigações e reflexões. Esta tarefa - já iniciada no âmbito do projeto RaisExpo, que tem levado a cabo a recolha sistemática da fortuna crítica de Rui Mário Gonçalves, procurando entender a sua relação com a FCG, principalmente com as exposições - deve continuar a ser empreendida e complementada com novas fontes documentais e de arquivo. O nome de Rui Mário Gonçalves enquadra-se, então, no cumprimento de um novo posicionamento disciplinar, que se ocupa da historiografia das exposições, dos seus métodos, contextos, instituições e, como não podia deixar de ser, dos seus protagonistas.

MIDAS, 7 | 2016 
BIBLIOGRAFIA

“1200 Obras Recusadas na Exposição Gulbenkian.” 1961. Jornal de Letras e Artes, 13 dezembro, n.ำ

11, p. 2 e 11.

“A Situação da Arte em Portugal. Mesa Redonda...” 1970. Jornal de Letras e Artes, abril, p. 8-20.

“Chamo a Atenção para a Pop-art Abstracta" (Entrevista a Rui Mário Gonçalves). 1965. Jornal de Letras e Artes, 20 de outubro, p. 16.

“Entrevista com Rui Mário Gonçalves.” 1963. Jornal de Letras e Artes, 3 de julho, p. 1.

"Noticiário: O Primeiro Encontro de Críticos de Arte Portuguesa." 1967. Arquitetura. Revista de Arte e Construção, n.ำ 96, março-abril, p. 86-87.

"Prémio de Crítica de Arte Rui Mário Gonçalves." 1963. Jornal de Letras e Artes, 12 de junho, p. 5.

“Prémio Gulbenkian Crítica de Arte.” 1964. Jornal de Letras e Artes, 20 de outubro, p. 16.

“Rui Mário Gonçalves.” 1964. Jornal de Letras e Artes, 23 de setembro, p. 12 e 16.

Alves, Margarida Brito. 2007. A Revista Colóquio/Artes. Lisboa: Edições Colibri e Instituto de História da Arte - Estudos de Arte Contemporânea da Faculdade de Ciências Sociais e Humanas da Universidade Nova de Lisboa.

Baião, Joana. 2016. "Memórias de Exposições: o Projeto RaisExpo.” MIDAS - Museus e Estudos Interdisciplanes 6.

França, José-Augusto. 1964. “1954-1964: Uma Década de Pintura e Escultura na «Tate Gallery» de Londres.” Jornal de Letras e Artes, 16 de julho, p. 10.

Freitas, Helena de, e Jorge Molder, coord. 2007. Amadeo de Souza Cardoso, Fotobiografia: Catálogo Raisonné. Lisboa: Fundação Calouste Gulbenkian.

Freitas, Helena de, e Jorge Molder, coord. 2008. Amadeo de Souza Cardoso, Pintura: Catálogo Raisonné. Lisboa: Fundação Calouste Gulbenkian.

Gonçalves, Rui Mário. 1962a. “A II Exposição da Fundação Gulbenkian.” Jornal de Letras e Artes, 10 de janeiro, p. 8-10 e 14.

Gonçalves, Rui Mário. 1962b. “A Terceira Geração na II Exposição Gulbenkian.” Jornal de Letras e Artes, 7 de março, p. 10 e 15.

Gonçalves, Rui Mário. 1962c. “Exposição “Arte Britânica no Séc. XX”. Jornal de Letras e Artes, 4 de abril, p. 10.

Gonçalves, Rui Mário. 1964. "Pintura e Escultura duma Década, 1954-64.” Arquitetura: Revista de Arte e Construção, novembro, n..$^{84, ~ p . ~ 147-156 . ~}$

Gonçalves, Rui Mário. 1965a. “Entrevista a Carlos Cobra.” Jornal de Letras e Artes, 28 de julho, pp. 4 e 15.

Gonçalves, Rui Mário. 1965b. “Entrevista com José Escada”. Jornal de Letras e Artes, 25 de agosto, pp. 16 e 15.

Gonçalves, Rui Mário. 1965c. “Aureliano Lima.” Jornal de Letras e Artes, 8 de setembro, p. 16. 
Gonçalves, Rui Mário. 1966a. “Manuel Cargaleiro.” Jornal de Letras e Artes, 21 de setembro, p. 16. Gonçalves, Rui Mário. 1966b. Seis Pintores Portugueses de Paris. Lisboa: Galeria Buchholz. Gonçalves, Rui Mário. 1967. “O Primeiro Encontro de Críticos de Arte Portugueses.” Colóquio. Revista de Artes e Letras, n.․ 44, junho, p. 12-17.

Gonçalves, Rui Mário. 1968. “Doze Meses de Artes Plásticas. Desfasamento entre a Arte e a Sociedade." O Século, 1 de janeiro, p. 12-17.

Gonçalves, Rui Mário. 1969. “A última temporada (2).” A Capital. Suplemento Literatura \& Arte, 1 de outubro, p. 8.

Gonçalves, Rui Mário. 1970. “Depois de uma Exposição.” A Capital, 26 de julho, n.ำ 901, p. 1. Gonçalves, Rui Mário. 1992. “A Década do Silêncio: 1951-1960.” In Arte Portuguesa nos Anos 50: Tendências e Situações de Vanguarda nos Anos 50 [catálogo de exposição], s/p. Lisboa: Fundação Calouste Gulbenkian.

Gonçalves, Rui Mário. 2006. “Salto Notável." Jornal de Letras, Artes e Ideias, 5-18 julho, n.o 933, p. 20-21.

Gonçalves, Rui Mário. 2014. “As Escolhas dos Críticos: Joan Miró por Rui Mário Gonçalves [depoimento vídeo].” Museu Coleção Berardo. URL: http://bit.ly/1H6atks

Jornal de Letras e Artes. 1953. 12 de junho, p. 5.

Macedo, Rita. 2009. “1968-74. Renovação na Continuidade.” In Anos 70: Atravessar Fronteiras, organizado por Raquel Henriques da Silva, e Ana Filipa Ruivo, 19-26. Lisboa: Fundação Calouste Gulbenkian.

Oliveira, Leonor. 2013a. "Fundação Calouste Gulbenkian: Estratégias de Apoio e Internacionalização da Arte Portuguesa 1957-1969.” Tese de Doutoramento em História de Arte, Universidade Nova de Lisboa.

Oliveira, Leonor. 2013b. "Politics, Diplomatic Relations and Institutional Promotion through Modern Art - The British Art of the Twentieth Century Exhibition in Portugal, 1962." RIHA Journal 0072.

Pena, Gonçalo. 1994. "Instituições, Galerias e Mercados." In Anos 60. Anos de Ruptura: Uma Perspetiva da Arte Portuguesa nos Anos Sessenta, organizado por António Rodrigues, s/p. Lisboa: Livros Horizonte.

Pernes, Fernando. s/d. “Exposições de Lisboa.” Jornal de Letras e Artes, n.․ 268, p. 35.

Pinharanda, João. 1995. “O Declínio das Vanguardas: dos Anos 50 ao Fim do Século.” In História da Arte Portuguesa, 602-638. Vol. III. Lisboa: Círculo de Leitores.

Pinharanda, João. 2014. “Rui Mário Gonçalves: Para Memória Futura.” Revista Visão, 20 de maio. http://visao.sapo.pt/jornaldeletras/artesvisuais/rui-mario-goncalves-para-memoriafutura $=\mathrm{f} 780867$

Rodrigues, António. 1994. “Anos de Ruptura." In Anos 60. Anos de Rutura: Uma Perspetiva da Arte Portuguesa nos Anos Sessenta, organizado por António Rodrigues, s/p. Lisboa: Livros Horizonte.

Rosa, António Ramos. 1971. “Todas as Possíveis Possibilidades.” A Capital, supl. Literatura \& Arte, 13 de outubro, p. 1.

Rosendo, Catarina. 2012. “A Crítica de Arte Debaixo de Fogo: 'Serviço de Utilidade' ou 'Moral de Combate'? O I Encontro dos Críticos de Arte (1967) e os escritos de António Areal.” Comunicação 
apresentada no IV Congresso de História da Arte Portuguesa - Homenagem a José-Augusto França, Lisboa. http://bit.ly/1ILWA9i

Silva, Raquel Henriques da. 2009. “Os Anos 70 depois do 25 de Abril." In Anos 70. Atravessar Fronteiras, org. Raquel Henriques da Silva, e Ana Filipa Ruivo, 26-31. Lisboa: Fundação Calouste Gulbenkian.

Silva, Raquel Henriques da. 2014. “A Coleção do CAM, um Desígnio Nacional: Divulgar, Partilhar e Valorizar a Arte Moderna Contemporânea." In 30 Anos Centro de Arte Moderna Fundação Calouste Gulbenkian, coordenação de Nuno Grande, 118-165. Lisboa: CAM - Fundação Calouste Gulbenkian.

\section{NOTAS}

1. Projeto do Gabinete da Presidência da FCG desenvolvido em parceria entre esta instituição e o Instituto de História da Arte da Faculdade de Ciências Sociais e Humanas da Universidade Nova de Lisboa. É coordenado por Helena de Freitas (FCG) e por Raquel Henriques da Silva (Instituto de História da Arte). Para maior detalhe veja-se Baião (2016).

2. Refira-se que a FCG fez várias aquisições de obras de arte a esta galeria, durante a direção artística de Rui Mário Gonçalves, o que, de certo modo, é um indicador do reconhecimento que aquela instituição dava aos seus critérios artísticos. Destas transações destaca-se a aquisição de obras de Lourdes Castro (Odalisque d'Après Ingres, 1964) e de Eduardo Luiz (Ardoise à l'Artichaud, 1965) no ano de 1967, no contexto de organização da grande exposição de itinerância internacional Arte Portuguesa - Pintura e Escultura do Naturalismo aos Nossos Dias, organizada em parceria com o Secretariado Nacional de Informação (1967-1968, montagens em Bruxelas, Paris e Madrid), e para a aquisição de uma obra de Álvaro Lapa (Voici nos Acteurs, William, 1972) para a exposição Pintura Portuguesa de Hoy: Abstractos y Neofigurativos (1973, montagens em Barcelona, Salamanca e Lisboa), organizada conjuntamente com a Secretaria de Estado de Informação e Turismo (Arquivo da Fundação Calouste Gulbenkian, SBA 12752 e SBA 12935). Tendo em conta estes dados, não deixa de ser estranha, tal como já apontou Raquel Henriques da Silva, a ausência de Rui Mário Gonçalves na Comissão de compras da FCG para o futuro Centro de Arte Moderna, já que a sua presença «não alteraria os resultados mas poderia ter conduzido ao seu afinamento» (Silva 2014, 125, nota 32).

3. O prémio, instituído em 1961, previa a atribuição de $15.000 \$ 00$ (primeiro lugar) ao «melhor trabalho de Crítica de Arte publicado no decurso de cada ano. Admitem-se ao concurso críticas publicadas em revistas ou jornais nacionais ou estrangeiros, assinadas por autores portugueses ou de outra nacionalidade, desde que sejam dedicadas a manifestações artísticas realizadas no País ou no estrangeiro, quando de interesse para Portugal [...]» ("1200 Obras recusadas na Exposição Gulbenkian" 1961, 2 e 11).

4. Em 1965, Rui Mário Gonçalves comentaria que o "panorama da crítica é mau» ("Chamo a atenção para a pop-art abstracta” 1965, 16). Anos mais tarde, este crítico viria a recordar que, neste período, a «reflexão estética capaz de encontrar as correlações tinha pouca presença nos meios de difusão» e que o público, inadvertidamente, convivia com a «oficialidade elogiar pomposamente as estátuas e monumentos do mais chilro academismo» (Gonçalves 1992, 92).

5. Gonçalves (1962a; 1962b). Refiram-se as repercussões que tiveram os pressupostos críticos de Rui Mário Gonçalves referentes a esta exposição, onde apareceu como pioneiro a utilizar o termo «novo-figurativismo», que em parte contribuiu para atenuar a radicalização em torno da oposição entre abstração e figuração (v. Oliveira 2013a, 298-302; e Pinharanda 1995, 593-594).

6. Gonçalves (1962c). Sobre esta exposição ver a leitura atualizada proposta por Oliveira (2013b). 
7. Em 1962, Rui Mário Gonçalves substituiu Fernando Pernes, que partira para Paris com uma bolsa de estudo de especialização concedida pela FCG, na direção da secção de «Artes Plásticas» do Jornal de Letras e Artes.

8. Por exemplo, Fernando Pernes, também colaborador do Jornal de Letras e Artes neste período, foi galardoado com o Prémio em 1965.

9. Arquivo da FCG, SBA 01027, correspondência trocada entre Rui Mário Gonçalves e o Serviço de Belas Artes da FCG.

10. Idem.

11. V. Jornal de Letras e Artes: "Entrevista a Rui Mário Gonçalves" (23 de setembro de 1964); "Entrevista a Carlos Cobra" (28 de julho de 1965); "Entrevista com José Escada" (25 de agosto de 1965); "Aureliano Lima” (8 de setembro de 1965); "Chamo a Atenção para a Popart Abstrata" (3 de julho de 1965); e "Manuel Cargaleiro" (21 de setembro de 1966).

12. A exposição teve igualmente efeitos no próprio reposicionamento e reequilíbrio das políticas internas da FCG, evidente desde logo no ano que se seguiu, quando foi assumido o encargo de

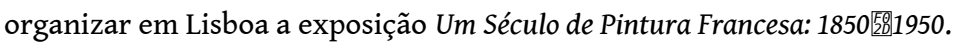

13. «E manobras como esta em que os ingleses têm ao mesmo tempo papel de atores e de vítimas... A ingenuidade das afirmações americanas [...], encontrou eco na manifestação londrina, teleguiou-a, impôs-lhe preceitos doutrinários. Ao desejarem marcar independência perante Paris [...], os ingleses tornaram-se dependentes dos Americanos. No fundo, fizeram mau negócio e ainda pior figura...» (cf. França 1964, 10).

14. «[...] Desde os Impressionistas até à última guerra, Paris foi o centro privilegiado da Arte Moderna, devido a factores de ordem geográfica, política, etc., e também devido a factores puramente culturais. Entre os factores de ordem política, por exemplo, citem-se a mudança por parte do governo soviético da sua política cultural e a perseguição nazi aos artistas de vanguarda. Se não se tivessem dado esses dois factos, a escola de Paris não teria talvez conhecido tanta evidência depois do Fauvismo e do Cubismo. Outros centros de arte poderiam então ter-se desenvolvido» (“Rui Mário Gonçalves” 1964, 12).

15. O I Encontro de Críticos de Arte Portugueses, que teve lugar entre 28 e 31 de março de 1967, foi organizado pelo Centro Nacional de Cultura, orientado por José-Augusto França, Adriano de Gusmão, Nuno Portas e secretariado por Rui Mário Gonçalves. Acerca deste evento, v. "Noticiário: O Primeiro Encontro de Críticos de Arte Portuguesa" (1967, 86-87) e "A Situação da Arte em Portugal. Mesa Redonda..." (1970, 8-20).

16. «No final, foram apresentadas algumas moções, que foram aprovadas unanimemente pelos presentes:

- Que a Fundação Calouste Gulbenkian crie, em Lisboa, periodicamente e devidamente programadas, grandes exposições internacionais de Arte Contemporânea com a atribuição de prémios significativos;

- Que a Fundação Calouste Gulbenkian promova a estruturação de um plano de estudo nos domínios da arquitetura e do urbanismo para desenvolver tema prioritários exequíveis, usando meios de trabalho atuais:

a) Ciências humanas (nomeadamente sociologia urbana), estética e teoria da arquitetura;

b) Metodologia crítica e pedagógica.

- Que a Fundação Calouste Gulbenkian promova pesquisas e inquéritos devidamente orientados que levem ao conhecimento dos problemas da vida artística portuguesa, de modo a permitir o estudo das soluções mais convenientes e eficazes» (Gonçalves 1967, 16).

17. «Mas também as iniciativas nos domínios da crítica sofrem de abandono igual ao que se verifica nos domínios da arte [...]. Bastará lembrar que nesta iniciativa [...], não quiseram colaborar organismos com responsabilidades culturais, como a Secção Portuguesa da Associação 
Internacional dos Críticos de Arte, a Sociedade Nacional de Belas-Artes e o Secretariado Nacional de Informação. Apenas a Fundação Gulbenkian se fez representar [...]» (Gonçalves 1968, 10).

18. Nomeadamente, através da integração de novos membros. Sobre este assunto, Rui Mário Gonçalves viria a comentar: «Deu-se este ano um passo importante para a reestruturação da Secção [portuguesa da AICA]. J.-A. França transitou da secção francesa, a que pertencia, para a portuguesa e [...] convidou a aderir à A.I.C.A. as quatro pessoas a quem a Fundação Gulbenkian tinha atribuído um prémio de crítica de arte: Mário de Oliveira (1962), Rui Mário Gonçalves (1963), Nuno Portas (1964) e Fernando Pernes (1965). O meu primeiro cuidado ao aderir à A.I.C.A., foi protestar contra este critério, que revelava falta de personalidade: não há que seguir critérios alheios para escolher os próprios sócios [...]» (Gonçalves 1969, 8).

19. Este evento foi um retumbante sucesso, tendo contado com cerca de 40000 visitantes.

20. Estas são as visitas guiadas por Rui Mário Gonçalves registadas nos processos consultados no Arquivo da FCG. Contudo, poderão existir registos de outras visitas em documentação ainda não estudada. A verificar-se apenas um período tão curto de colaboração entre Gonçalves e a FCG neste domínio, será interessante, no futuro, apurar as suas causas.

21. Esta exposição está a ser estudada no âmbito do projeto de mestrado em Museologia (Universidade Nova) de Carolina Matias, orientado por Leonor de Oliveira e coorientado por Helena de Freitas e integrado no projeto "RaisExpo - Catálogo Raisonné Online das Exposições de Arte da Fundação Calouste Gulbenkian".

22. Sobre este importante evento v. Oliveira (2013a).

\section{RESUMOS}

Rui Mário Gonçalves (1934-2014) é um nome incontornável da crítica da arte portuguesa. A sua ação estendeu-se por várias décadas e deixou marcas no panorama cultural português. Partindo da análise da documentação disponível no arquivo da Fundação Calouste Gulbenkian (FCG), são elencados alguns momentos do relacionamento de Rui Mário Gonçalves com esta instituição. Verifica-se a importância da FCG quer no seu período formativo, por via da concessão de uma bolsa de estudo em Paris, quer posteriormente, nos anos de afirmação e consolidação da sua carreira como historiador e crítico de arte. Neste campo, é dado especial enfoque à sua relação com as exposições promovidas pela FCG, quer enquanto crítico, quer enquanto seu interveniente direto. Não se pretendendo neste artigo fazer uma revisão da biografia cultural e artística de Rui Mário Gonçalves, pretende-se contudo dar um primeiro contributo para o estudo desta personalidade e da sua ação, assinalando vários temas que poderão - e deverão - ser alvo de futuras investigações.

The critic and art historian Rui Mário Gonçalves (1934-2014) is an essential personality within the Portuguese cultural milieu. His action lasted for several decades, from the 1960's onwards, leaving his mark on Portuguese contemporary art historiography. Based on the analysis of the Calouste Gulbenkian Foundation (FCG)'s archives, some of the most important moments in the relationship between Rui Mário Gonçalves and the FCG are listed - from his formative period, which was marked by his stay in Paris (supported by this institution), to the affirmation and consolidation of his career as an historian and art critic. In this respect, special attention is given to his role in the exhibitions promoted by the FCG, either as a critic or as a direct participant. Rather than offering an in-depth review of Rui Mário Gonçalves's cultural and artistic biography, 
this article aims to give a contribution to the study of his life and activity, pointing out several issues that could - and should - be the subject of future research.

\section{ÍNDICE}

Palavras-chave: Rui Mário Gonçalves, Fundação Calouste Gulbenkian, crítica de arte, exposição, história das exposições

Keywords: Calouste Gulbenkian Foundation, art criticism, exhibition, history of exhibitions

\section{AUTORES}

\section{FILIPA COIMBRA}

Licenciada em História da Arte pela Faculdade de Letras da Universidade de Coimbra (2008), mestre em Crítica de Arte e Arquitetura pelo Colégio das Artes da mesma Universidade (2013) e doutoranda em História da Arte na Faculdade de Ciências Sociais e Humanas da Universidade Nova de Lisboa. Colaborou com o Serviço Educativo da Casa das Histórias Paula Rego (2009-2011) e atualmente é investigadora no âmbito do projeto "RaisExpo - Catálogo Raisonné Online das Exposições de Arte da Fundação Calouste Gulbenkian".

Fundação Calouste Gulbenkian, Av. de Berna, 45A, 1067-001 Lisboa, Portugal, fcoimbra@gulbenkian.pt

\section{JOANA BAIÃO}

Membro integrado do Instituto de História da Arte da Faculdade de Ciências Sociais e Humanas da Universidade Nova de Lisboa, onde está a desenvolver o projecto de pós-doutoramento. Licenciada em Escultura pela Faculdade de Belas-Artes da Universidade de Lisboa (2005), mestre em Museologia pela Universidade Nova (2009) e doutora em História da Arte - especialização em Museologia e Património Artístico na mesma Universidade (2014). Tem colaborado com várias instituições culturais portuguesas (Museu Nacional de Arte Contemporânea - Museu do Chiado; Museu Coleção Berardo; e Fundação Arpad Szenes - Vieira da Silva). Atualmente, é assistente de coordenação do projeto "RaisExpo - Catálogo Raisonné Online das Exposições de Arte da Fundação Calouste Gulbenkian".

Instituto de História da Arte, Faculdade de Ciências Sociais e Humanidades da Universidade Nova de Lisboa, Av. de Berna, 26-C, 1069-061 Lisboa, Portugal, joanagreg@gmail.com 